\title{
Adherence to hepatitis A and hepatitis B multi-dose vaccination schedules among adults in the United Kingdom: a retrospective cohort study
}

Kelly D. Johnson ${ }^{1,2^{*}}$, Xiaoyan $\mathrm{Lu}^{3}$ and Dongmu Zhang ${ }^{1}$

\begin{abstract}
Background: Timely and complete vaccination with multi-dose schedules is of public health importance, because an incomplete vaccination series may yield suboptimal disease protection. However, data on adherence of adults to multi-dose vaccines are limited. We sought to estimate adherence to multi-dose hepatitis vaccination schedules among adults in the United Kingdom (UK).

Methods: This retrospective cohort study was conducted using anonymized electronic health record (EHR) data from the Clinical Practice Research Datalink (CPRD). Individuals aged 19 years and older at their first identified dose of hepatitis vaccine (2009-2016) were included if they had continuous EHR data for 12 months before the first identified hepatitis A dose or for 6 months before the first identified hepatitis B or combination hepatitis A/B dose. We estimated dose and series completion for each vaccine and adherence to recommended vaccination schedules, as well as adherence within additional prespecified time periods after the first vaccine dose, with sensitivity analyses restricted to adults who had available data for up to 24 months after the first dose. Median time to series completion was estimated using Kaplan-Meier methods.
\end{abstract}

Results: Mean (SD) age at initiation was 42 (16) years for hepatitis A $(n=374,881), 40$ (16) years for hepatitis B $(n=71,634)$, and 38 (15) years for hepatitis $A / B(n=10,335)$. Women comprised 52 to $55 \%$ of each vaccine cohort. Overall, 42,294 adults (11\%) completed the two-dose hepatitis A vaccine series within the recommended 12 months; and 15,564 (22\%) and 1076 (10\%) completed the three-dose hepatitis B and hepatitis A/B series, respectively, within the recommended 6 months. These percentages rose to only 23,35 , and $33 \%$, respectively, when the follow-up periods were extended to 36 months for hepatitis A and to 30 months for hepatitis B and A/B vaccines. Median times to series completion within recommended schedules were not reached in any cohort. Sensitivity analyses supported the primary findings for the full cohorts.

Conclusions: Adherence and series completion rates for hepatitis A and B vaccines in the UK are low. Identifying, understanding, and addressing barriers to series completion for multi-dose vaccines for adults in real-world settings are needed.

Keywords: Hepatitis A, Hepatitis B, Hepatitis A/B, Multi-dose, Series completion, Vaccination

\footnotetext{
* Correspondence: kelly.johnson@merck.com

${ }^{1}$ Center for Observational and Real World Evidence (CORE), Merck \& Co., Inc., Kenilworth, NJ, USA

${ }^{2}$ Center for Observational and Real World Evidence (CORE), Merck \& Co., Inc., UG2AB-30, 351 N. Sumneytown Pike, North Wales, PA 19454, USA

Full list of author information is available at the end of the article
}

(c) The Author(s). 2019 Open Access This article is distributed under the terms of the Creative Commons Attribution 4.0 International License (http://creativecommons.org/licenses/by/4.0/), which permits unrestricted use, distribution, and reproduction in any medium, provided you give appropriate credit to the original author(s) and the source, provide a link to the Creative Commons license, and indicate if changes were made. The Creative Commons Public Domain Dedication waiver (http://creativecommons.org/publicdomain/zero/1.0/) applies to the data made available in this article, unless otherwise stated. 


\section{Background}

Timely and complete vaccination with multi-dose schedules is of public health importance, because an incomplete vaccination series may yield suboptimal disease protection. Most studies investigating completion of multi-dose vaccine schedules have been conducted for pediatric and adolescent populations [1-3], for whom several different multi-dose vaccines are recommended. Instead little information is available regarding adherence to and completion of multi-dose vaccine series among adults.

Hepatitis A and hepatitis B are vaccine-preventable viral diseases of the liver [4-7] for which effective multi-dose vaccines have been available for many years. In the United Kingdom (UK), hepatitis A and/or hepatitis B vaccinations are recommended for adults at high risk of exposure to the specific virus or of complications from the disease $[8,9]$, among them travelers to high-risk countries, health care providers, intravenous drug users, sex workers, prisoners, patients with chronic liver disease, and any persons at risk of contact with blood or body fluids [10]. All recommended vaccinations are provided for free by the UK National Health Service (NHS). The usual recommended vaccination schedules are for two doses of the hepatitis A vaccine within 12 months, and for three doses of the hepatitis $B$ or combination hepatitis $\mathrm{A} / \mathrm{B}$ vaccine within 6 months.

Studies of adults in countries of low hepatitis prevalence, such as the UK, United States (US), Canada, and western Europe, indicate that hepatitis A and B vaccine series completion rates among adults are low [11-16]. For example, in a large 2015 survey in the US, only 16 and $32 \%$ of travelers to countries of high to intermediate endemicity had completed the two- or three-dose series for hepatitis $A$ or hepatitis $B$, respectively [11]. The majority of studies of hepatitis vaccine series completion, however, are done in circumscribed populations such as the homeless [14], travelers [15], and adults with chronic liver disease [16].

There are few studies of series completion for multi-dose vaccinations in broad, general adult populations, and few studies have examined the rates of vaccine series completion within the recommended time frames [13], including none in the UK. We conducted a population-level analysis of vaccination completion rates using a large routinely collected dataset in the UK [17]. The primary objective of this study was to estimate dose and series completion for hepatitis $A$, hepatitis $B$, and combination hepatitis $A / B$ multi-dose vaccines and adherence to the two- and threedose vaccination schedules among adults in the UK receiving care under the umbrella of the NHS.

\section{Methods}

\section{Data source}

This retrospective cohort study used anonymized electronic health record (EHR) data from the Clinical Practice
Research Datalink (CPRD), a large, well-managed database maintained by the UK Department of Health and Social Care [17]. Used frequently for pharmacoepidemiological research, the CPRD contains longitudinal EHR data that originates from over 600 subscribing general practices throughout the UK, representing about 5 million patients with active EHRs, or $7 \%$ of the UK population.

We used CPRD data from January 1, 2009, through December 31, 2016. The protocol for this study was approved by the CPRD Independent Scientific Advisory Committee (ISAC reference number 17_226R). No patient identifying information was accessible during the study.

\section{Study population}

Adults who had a recorded dose of hepatitis A, hepatitis $\mathrm{B}$, or hepatitis $\mathrm{A} / \mathrm{B}$ vaccine at 19 years of age or older were eligible for the study. We required individuals receiving the hepatitis A vaccine to have at least 12 months of continuous baseline data before their first identified dose, while those receiving hepatitis $B$ or hepatitis $A / B$ vaccine were required to have at least 6 baseline months. The 12-month (hepatitis A) and 6-month (hepatitis B and A/ B) baseline data requirements were selected to maximize the possibility that we identified the initiation of a vaccination series in the database rather than a booster.

Patients on hemodialysis who received an altered hepatitis $B$ vaccination schedule or dosage were excluded from the study. In addition, individuals who received a second dose of the hepatitis A/B vaccine within 2 weeks of the first dose were excluded, as this schedule indicates use of accelerated administration requiring a total of four vaccines.

\section{Outcome measures}

The primary study outcomes were (1) completion of the recommended number of doses of the relevant hepatitis vaccine (series completion) and (2) adherence to the recommended timing of the 2-dose hepatitis $\mathrm{A}$ and 3-dose hepatitis $\mathrm{B}$ and hepatitis $\mathrm{A} / \mathrm{B}$ vaccines as per UK labeling for each vaccine product (Table 1) [18]. We calculated the proportions of adults who completed two and three doses and the proportions who adhered to the recommended schedule or within prespecified additional time periods after the first dose, as outlined in Table 1. In addition, we estimated the median time to completion of each dose and each vaccination series.

\section{Statistical analysis}

The study population was stratified by first vaccine type (hepatitis A, B, or combination $\mathrm{A} / \mathrm{B}$ ), and each vaccine cohort was analyzed separately. Therefore, if an individual received both hepatitis $A$ and hepatitis $B$ vaccines during the study period, that individual would be included in both vaccine cohorts. Results for series completion and 
Table 1 Recommended adult administration schedules for hepatitis A, B, and A/B vaccine products in the United Kingdom

\begin{tabular}{|c|c|c|c|c|}
\hline \multirow[t]{2}{*}{ Vaccine } & \multicolumn{3}{|c|}{ Recommended schedule } & \multirow{2}{*}{$\begin{array}{l}\text { Additional study time } \\
\text { points for completion } \\
\text { assessments }^{\mathrm{a}}\end{array}$} \\
\hline & Dose 1 & Dose $2^{a}$ & $\overline{\text { Dose } 3^{a}}$ & \\
\hline Hepatitis A & 0 & $6-12 \mathrm{mo}^{\mathrm{b}}$ & $\mathrm{n} / \mathrm{a}$ & $\begin{array}{l}\text { Dose 2: } \\
\text { At } 24 \mathrm{mo} \text { and } 36 \mathrm{mo}\end{array}$ \\
\hline Hepatitis B & 0 & $1 \mathrm{mo}$ & $2-6 \mathrm{mo}$ & $\begin{array}{l}\text { Dose 2: } \\
\text { At } 13 \mathrm{mo} \text { and } 25 \mathrm{mo}\end{array}$ \\
\hline Hepatitis A/B & 0 & $1 \mathrm{mo}$ & $6 \mathrm{mo}$ & $\begin{array}{l}\text { Dose 3: } \\
\text { At } 18 \mathrm{mo} \text { and } 30 \mathrm{mo}\end{array}$ \\
\hline
\end{tabular}

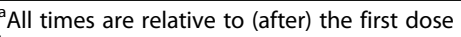

${ }^{\mathrm{b}}$ Administration of the second dose of VAQTA ${ }^{\oplus}$ (Merck Sharp \& Dohme, Hoddesdon, Hertfordshire, UK) is recommended at 6-18 months after the first dose [18], but for study purposes adherence was defined as 6-12 months mo month; $n / a$ not applicable (2-dose vaccine)

adherence were evaluated for the full cohorts and stratified by age at first dose within each cohort (19-49, 50-59, $60-64,65-69$, and $\geq 70$ years). Baseline and outcome measures were summarized descriptively using means, medians, 95\% confidence intervals (CIs), standard deviations, and frequency distributions for categorical variables.

We used Kaplan-Meier (KM) methods to estimate the time to completion of the second and third dose (as appropriate) at prespecified time points after series initiation. Only individuals with complete information for all the variables in the model were included in the study; hence there was no imputation for missing data. The use of the KM method allowed for inclusion of full vaccine cohorts by right-censoring of records for those without evidence of series completion. These individuals were censored at the end of the data. Survival function by age group was compared with the reference group of oldest adults (age $\geq 70$ years) by calculation of hazard ratios (HR) with 95\% CI.

We conducted sensitivity analyses to assess the impact of requiring a longer continuous baseline (pre-vaccine) period of 24 months' data for the hepatitis A cohort and 18 months' data for hepatitis $\mathrm{B}$ and hepatitis A/B cohorts. In addition, we analyzed series completion for individuals in each vaccine cohort with continuous follow-up data after the first vaccine dose of 6,12 , 18 , and 24 months.

\section{Results}

\section{Vaccine cohorts}

The numbers of adults initiating a hepatitis vaccine series and eligible for the study are depicted in Additional file 1, Figure S1, and were greatest for hepatitis A $(n=374,881)$, followed by hepatitis B $(n=71,634)$ and hepatitis A/B $(n=$ 10,335). Most individuals in each vaccine cohort were 19 to 49 years old, with mean ages of 42,40 , and 38 years in hepatitis $\mathrm{A}, \mathrm{B}$, and $\mathrm{A} / \mathrm{B}$ cohorts, respectively (Table 2).
Table 2 Baseline characteristics of adults initiating a multi-dose hepatitis vaccination series from 2009 to 2016 in the UK

\begin{tabular}{|c|c|c|c|}
\hline & $\begin{array}{l}\text { Hepatitis A } \\
(N=374,881)\end{array}$ & $\begin{array}{l}\text { Hepatitis B } \\
(N=71,634)\end{array}$ & $\begin{array}{l}\text { Hepatitis } A / B \\
(N=10,335)\end{array}$ \\
\hline \multicolumn{4}{|l|}{ Sex, n (\%) } \\
\hline Male & $173,766(46.4)$ & $32,111(44.8)$ & $5001(48.4)$ \\
\hline Female & $201,111(53.6)$ & $39,521(55.2)$ & $5333(51.6)$ \\
\hline Unknown & $4(0)$ & $2(0)$ & $1(0)$ \\
\hline $\begin{array}{l}\text { Mean (SD) age at } \\
\text { initiation, years }\end{array}$ & $42.0(15.7)$ & $39.8(15.5)$ & $37.9(15.0)$ \\
\hline \multicolumn{4}{|l|}{ Age distribution, n (\%) } \\
\hline 19 to 49 years & $251,070(67.0)$ & $51,739(72.2)$ & $7814(75.6)$ \\
\hline 50 to 59 years & $61,859(16.5)$ & $10,760(15.0)$ & $1405(13.6)$ \\
\hline 60 to 64 years & $25,895(6.9)$ & $3836(5.4)$ & $491(4.8)$ \\
\hline 65 to 69 years & $18,716(5.0)$ & $2552(3.6)$ & 375 (3.6) \\
\hline$\geq 70$ years & $17,341(4.6)$ & $2747(3.8)$ & $250(2.4)$ \\
\hline \multicolumn{4}{|c|}{ Government office region, n (\%) } \\
\hline North East & $4852(1.3)$ & $1035(1.4)$ & $129(1.2)$ \\
\hline North West & $35,114(9.4)$ & 7735 (10.8) & $496(4.8)$ \\
\hline Yorkshire \& the Humber & $6068(1.6)$ & $1843(2.6)$ & $674(6.5)$ \\
\hline East Midlands & $6101(1.6)$ & $1050(1.5)$ & $131(1.3)$ \\
\hline West Midlands & $34,346(9.2)$ & $6037(8.4)$ & $996(9.6)$ \\
\hline East of England & $28,054(7.5)$ & $5469(7.6)$ & $1602(15.5)$ \\
\hline South West & $28,706(7.7)$ & $6006(8.4)$ & $1356(13.1)$ \\
\hline South Central & $43,778(11.7)$ & $8230(11.5)$ & $691(6.7)$ \\
\hline London & $58,582(15.6)$ & $14,124(19.7)$ & $1964(19.0)$ \\
\hline South East Coast & $42,440(11.3)$ & $6105(8.5)$ & $1180(11.4)$ \\
\hline Northern Ireland & $10,446(2.8)$ & $1450(2.0)$ & $226(2.2)$ \\
\hline Scotland & $33,459(8.9)$ & $4185(5.8)$ & $251(2.4)$ \\
\hline Wales & 42,935 (11.5) & 8365 (11.7) & $639(6.2)$ \\
\hline
\end{tabular}

Months of continuous data after initiation

\begin{tabular}{llll}
$\begin{array}{l}\text { Median (IQR) } \\
\text { Distribution, n (\%) }\end{array}$ & $43(21-68)$ & $40(19-64)$ & $39(19-64)$ \\
0-5 months & $18,655(5.0)$ & $4048(5.7)$ & $593(5.7)$ \\
6-11 months & $30,272(8.1)$ & $6243(8.7)$ & $889(8.6)$ \\
12-23 months & $57,213(15.3)$ & $11,442(16.0)$ & $1682(16.3)$ \\
24-35 months & $52,238(13.9)$ & $10,238(14.3)$ & $1508(14.6)$ \\
$\geq 36$ months & $216,503(57.8)$ & $39,663(55.4)$ & $5663(54.8)$ \\
\hline IQR interquartile range & & &
\end{tabular}

Women comprised just over half of each cohort. The regional proportions of individuals in each cohort were greatest in London, with similar proportions throughout the UK in hepatitis A and hepatitis B cohorts, while the hepatitis A/B cohort had lower proportions in Scotland and Wales and greater proportions in some regions of England (see Table 2). From 55 to $58 \%$ of individuals in each cohort had available data of $>36$ months in the CPRD after their first vaccine dose. 
Hepatitis A vaccine adherence and series completion A total of 42,294 adults (11\%) completed the second dose of hepatitis A vaccine within the recommended 12 months. These numbers increased to 76,649 (20\%) at 24 months and to $84,337(23 \%)$ at 36 months of follow-up after the first vaccine dose. Figure 1a depicts the series completion rates overall and stratified by age at 12, 24, and 36 months. The percentages of individuals completing the hepatitis A vaccine series within each prespecified time period were greatest in the three age groups from 50 to 69 years.

The KM curves for the time to completion of the second dose of hepatitis A vaccine are shown in Fig. 2a by age group. The KM estimate of median time (in months) to series completion was not reached (NR; interquartile range [IQR] 33.1-NR; 75\% of persons censored).

\section{Hepatitis B vaccine adherence and series completion}

Overall, 32,951 adults (46\%) were adherent with the schedule for the second dose of hepatitis B vaccine (received by 1 month after the first dose), and 15,564 (22\%) were adherent with the third dose (from 2 to 6 months after the first dose). Older adults $\geq 70$ years had the greatest adherence to this schedule, with 56 and 35\% receiving the second and third doses by 1 month and 2-6 months, respectively (Fig. 1b).

By 13 months after the first dose, 38,500 individuals (54\%) overall had received the second dose, numbers that by 25 months increased only slightly to 38,953 (54\%). For the third dose, 24,344 (34\%) and 25,016 (35\%) completed the series by 18 and 30 months, respectively. The oldest age stratum maintained the greatest adherence to second and third doses over these longer follow-up periods (Fig. 1b).

The KM estimate of median time to completion of the second dose of hepatitis B vaccine was 2.3 months (95\% CI $2.1-2.5 ; 45 \%$ of persons censored). The median KM time (in months) to series completion (third dose) was not reached (NR; IQR 6.97-NR; 64\% of persons censored). There was little change in the KM curves by age for the second dose after about 5 months (Fig. 2b) and for the third dose after about 12 months (Fig. 2c).

\section{Hepatitis A/B vaccine adherence and series completion}

Adherence to the hepatitis $A / B$ recommended schedule was $56 \%$ for the second dose $(n=5822)$ by 1 month, and $10 \%$ for series completion (receipt of the third dose; $n=$ 1076) by 6 months. As for the hepatitis A vaccine, adherence was greatest in the three middle age groups (50 to 69 years; Fig. 1c).

Completion of the second dose was achieved by 6739 adults (65\%) by 13 months and by 6807 (66\%) by 25 months. Completion of the third dose was achieved by 3276 adults $(32 \%)$ by 18 months, increasing by $1 \%$ to
3417 (33\%) by 30 months, again with the greatest percentages of series completers being in the 50 to 69-year-old age groups.

The median time to completion of the second dose, estimated by the KM method, was 1.2 months (95\% CI $1.2-1.2 ; 33 \%$ of persons censored). The median KM time to series completion (third dose) was not reached (NR; IQR 7.87-NR; 65\% of persons censored). The KM curves for completion of second and third doses by age group are depicted in Fig. $2 \mathrm{~d}$ and e.

\section{Sensitivity analyses}

Limiting the analyses to adults with 24 months of continuous baseline enrollment before initiation resulted in a decrease of $<1 \%$ in adherence to the second dose of hepatitis A vaccine, whereas adherence to the second and third doses of hepatitis $B$ and hepatitis $A / B$ increased slightly by $<1$ to $2 \%$ with the requirement of 18 months' continuous baseline enrollment (Table 3).

Requiring longer periods of continuous enrollment after initiating the three vaccine series resulted in slightly higher completion and adherence, but results were within 2 percentage points of those for the full cohorts (Table 3 ).

\section{Discussion}

The rates of adherence to and series completion of UK vaccination schedules for multi-dose hepatitis $\mathrm{A}$ and hepatitis B vaccines were low among adults in this retrospective observational study. The percentages of adults adhering to and completing the recommended multi-dose series were 11,22 , and $10 \%$ for hepatitis $\mathrm{A}$, hepatitis $\mathrm{B}$, and hepatitis $\mathrm{A} / \mathrm{B}$ vaccines, respectively. These percentages rose to only 23,35 , and $33 \%$, respectively, when the follow-up periods were extended to 36 months for hepatitis $\mathrm{A}$ and to 30 months for hepatitis $\mathrm{B}$ and $\mathrm{A} / \mathrm{B}$ vaccines, well beyond the recommended windows for vaccine series completion. Sensitivity analyses requiring longer periods of continuous data before and after vaccine series initiation supported the primary findings, with adherence rates within 2 percentage points. Overall, these analyses suggest substantial waste of health care resources, with vaccines delivered but likely suboptimal protection obtained because of incomplete vaccination series.

We found that individuals in the older age groups ( $\geq 50$ years old) tended to be more adherent than younger adults (19-49 years old). This may be because older adults received the hepatitis vaccine together with an influenza vaccine, recommended annually in the UK for individuals 65 years and older, or together with the shingles vaccine, recommended for adults at age 70 [10]. Both influenza and shingles vaccine are administered at no cost under UK NHS care [19]. The hepatitis A vaccine is recommended most for travelers, while hepatitis 

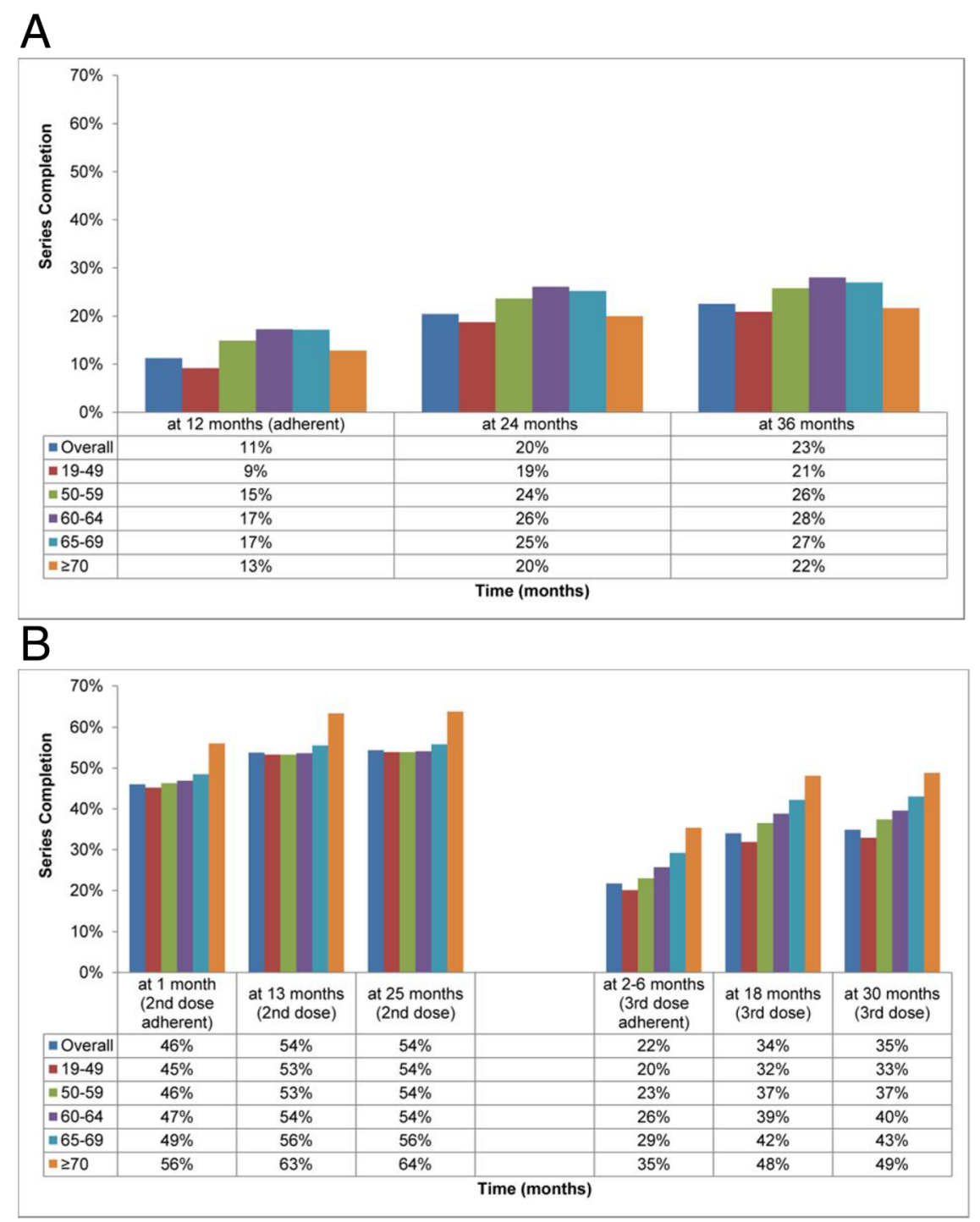

C

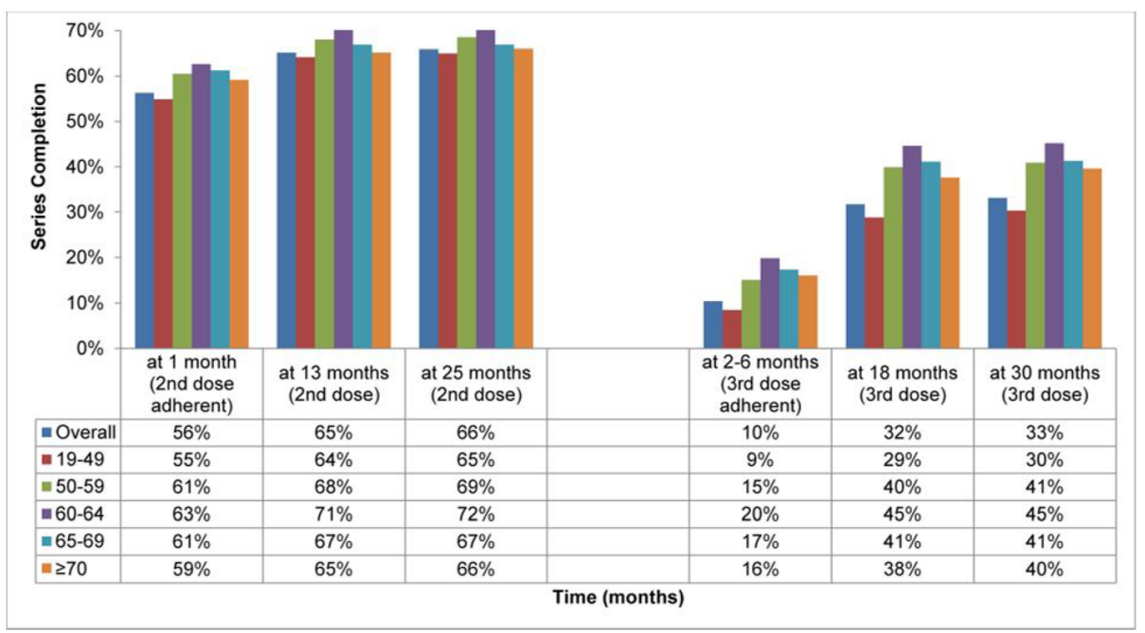

Fig. 1 Vaccine adherence and series completion rates overall and by age group for (a) hepatitis A vaccine, (b) hepatitis B vaccine, and (c) hepatitis A/B vaccine 


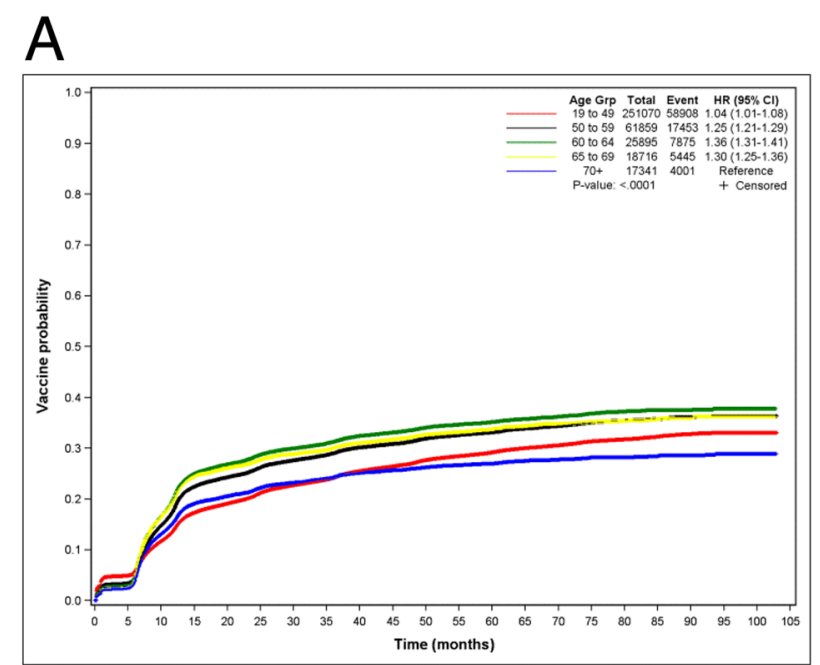

B

C
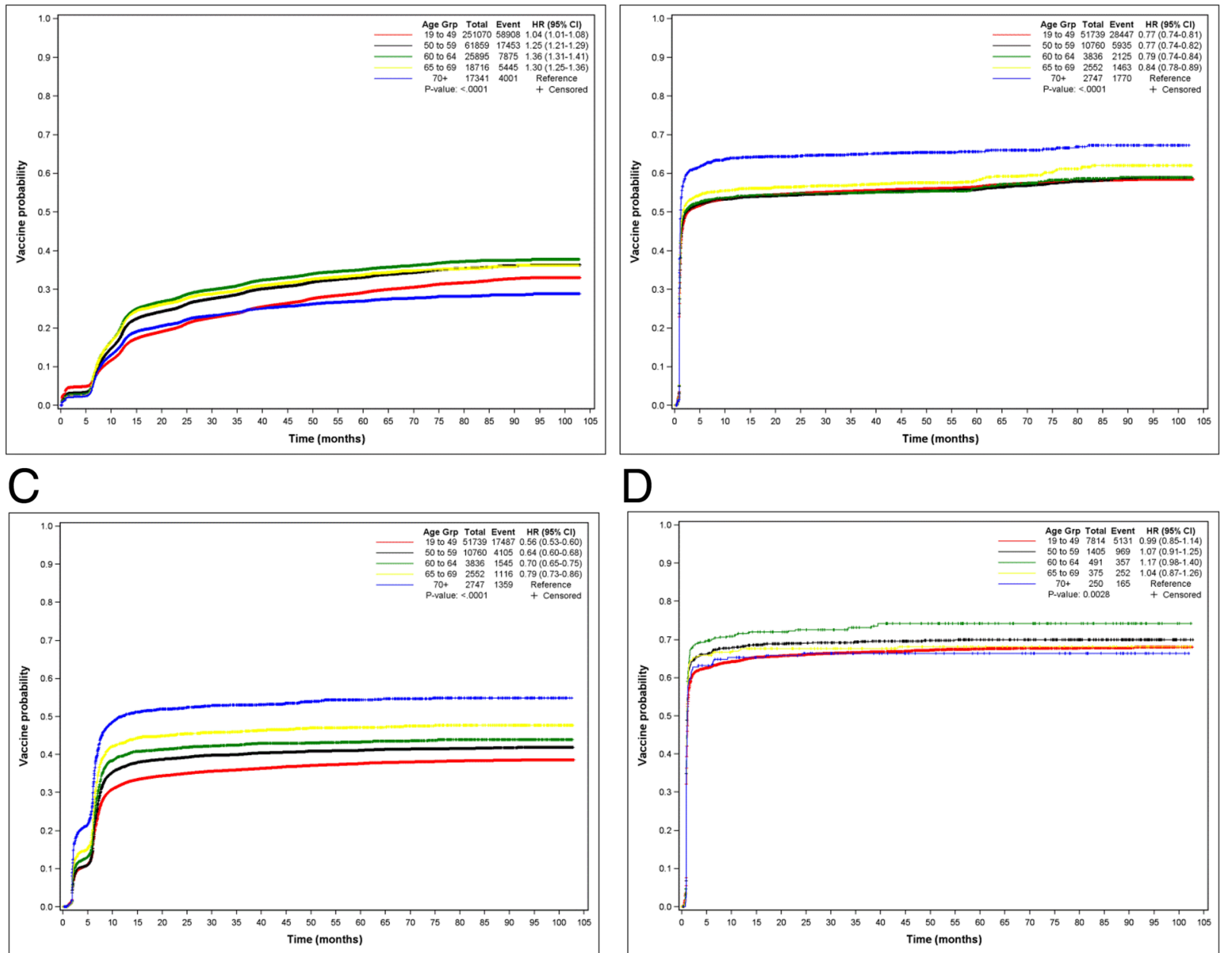

D

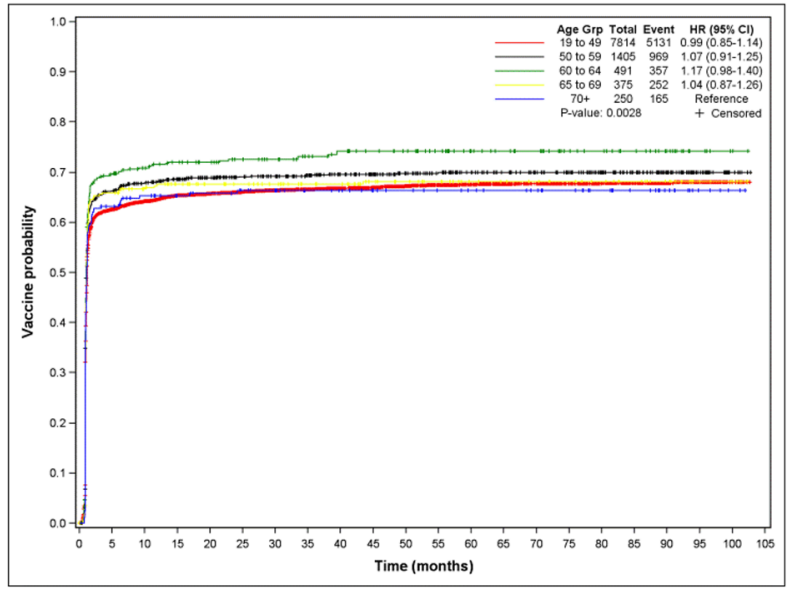

$\mathrm{E}$

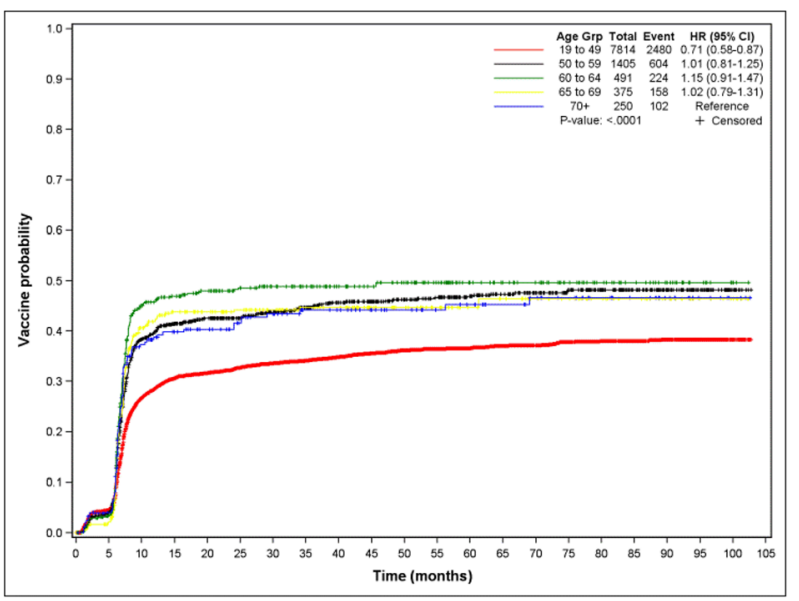

Fig. 2 Kaplan-Meier curves depicting time to series completion after initiation of each vaccine, by age group for the (a) second hepatitis A dose, (b) second hepatitis B dose, (c) third hepatitis B dose; (d) second hepatitis A/B dose, and (e) third hepatitis A/B dose. Age Grp age group; HR (95\% Cl) hazard ratio (95\% confidence interval) 
Table 3 Adherence to recommended vaccine schedules for all adults included in the study and for those included in sensitivity analyses with prespecified lengths of baseline (pre-vaccine) data and follow-up data after the first vaccine of the series

\begin{tabular}{|c|c|c|c|c|c|c|}
\hline \multirow[b]{2}{*}{ Adherence } & \multirow[b]{2}{*}{ All adults } & \multirow{2}{*}{$\begin{array}{l}\text { Baseline } \\
\text { 18/24-mo }\end{array}$} & \multicolumn{4}{|c|}{ Continuous data available in follow-up period } \\
\hline & & & 6 months & 12 months & 18 months & 24 months \\
\hline Hepatitis A, $n$ & 374,881 & 279,451 & 353,880 & 322,533 & 293,056 & 264,522 \\
\hline To 2nd dose, n (\%) & $42,294(11.3)$ & $30,020(10.7)$ & $42,266(11.9)$ & $41,056(12.7)$ & $38,134(13.0)$ & $34,851(13.2)$ \\
\hline Hepatitis $B, n$ & 71,634 & 52,734 & 67,076 & 60,685 & 54,872 & 49,142 \\
\hline To 2nd dose, n (\%) & $32,951(46.0)$ & $24,398(46.3)$ & $31,217(46.5)$ & $28,160(46.4)$ & $25,450(46.4)$ & $22,719(46.2)$ \\
\hline To 3rd dose, n (\%) & $15,564(21.7)$ & $11,588(22.0)$ & $15,321(22.8)$ & $13,888(22.9)$ & $12,574(22.9)$ & $11,251(22.9)$ \\
\hline Hepatitis A/B, n & 10,335 & 7746 & 9673 & 8764 & 7869 & 7056 \\
\hline To 2nd dose, n (\%) & $5822(56.3)$ & $4525(58.4)$ & $5534(57.2)$ & $5024(57.3)$ & $4481(56.9)$ & $4004(56.8)$ \\
\hline To 3rd dose, n (\%) & $1076(10.4)$ & $840(10.8)$ & $1073(11.1)$ & $1002(11.4)$ & 895 (11.4) & $808(11.5)$ \\
\hline
\end{tabular}

${ }^{a}$ Sensitivity analysis requiring continuous baseline (pre-vaccine) data of 24 months for the hepatitis A vaccine series and of 18 months for the hepatitis B and hepatitis $A / B$ vaccine series

$\mathrm{B}$ is recommended for both travelers and health-care providers, which could explain the considerably better adherence rates for the second dose of the hepatitis $\mathrm{B}$ vaccine $(46 \%)$ and combination hepatitis $A / B$ vaccine (56\%), as compared with the second dose of hepatitis A vaccine (11\%).

Few studies have examined multi-dose vaccine series completion in general adult populations. The recent study of Trantham et al. [13], designed similarly to the present study but using administrative claims data, reported somewhat higher, but still poor, rates of adherence in the US than in the UK, namely, rates of adherence to recommended schedules of 27,30 , and $18 \%$ for hepatitis $\mathrm{A}$, hepatitis $\mathrm{B}$, and hepatitis $\mathrm{A} / \mathrm{B}$, respectively. In addition, similar to the present study, they found that older adults had better adherence rates. The earlier study of Nelson et al. [20] in the US also found better adherence among older adult age groups and, for those adherent in all age groups, relatively long intervals between vaccine doses as in the present study and others [13].

Prior studies have reported suboptimal rates of series completion for hepatitis vaccine also in defined subpopulations, including patients with chronic liver disease [16], former prisoners [14], intravenous drug users [21], the homeless [22], and travelers [15, 23, 24]. Most of these studies did not examine series completion with regard to the recommended timelines.

Identification of the factors associated with adherence and dose/series completion was outside the scope of the present study; however, initiatives to improve patient and health care provider reminder systems, as well as opportunistic vaccination at other appointments, could be helpful to increase adherence and vaccination series completion. In a prior small study, Reynolds et al. [25] investigated factors associated with poor completion rates in a low-income minority population. They found that receipt of fewer doses of vaccine was associated with being male and having severe negative emotions, among other factors. The rate of three-dose series completions was only $31 \%$ despite the vaccinations being offered at no cost. Similarly, in our study, cost would not have been a potential barrier, because the NHS provides the vaccines for free. Offering financial incentives to encourage the return for second and third doses improved adherence in two studies of intravenous drug users [26, 27]; however, financial incentives were determined to not be a factor in series completion in a study of former prisoners [14]. Dedicated clinics have reported improved adherence when using multiple interventions, including SMS text reminders [28]. In addition, health-care provider recommendations to vaccinate are thought to be important, although studies find that providers, even at academic centers, often fail to adhere to hepatitis vaccination guidelines for patients with chronic liver disease [29, 30].

This study has several strengths. We used a large, high-quality database considered to have reliable capture of administered vaccinations [31] and that includes EHRs for a geographically diverse, representative UK population [32]. We studied almost half a million adults initiating hepatitis vaccination series, excluding patients receiving hepatitis $B$ vaccination while on hemodialysis as they may not be representative of the general adult population. In addition, we used the KM method, used in few prior studies [13, 33, 34], to determine time to completion of second and third doses. The study design enabled us to identify the probable first vaccine dose by requiring baseline data periods of 6 to 12 months, extended to 18 to 24 months, depending on vaccine type, in sensitivity analyses. The long follow-up, including sensitivity analyses examining continuous data for up to 36 months after the first vaccine, enabled us to study series completion as well as to examine in detail whether these multi-dose vaccines were administered at the recommended intervals. Of course, patients could receive a booster vaccine even 5 years after the original course, although the results of our 36-month follow-up analyses suggest that overall findings would not change. However, we acknowledge that only 
$55-58 \%$ of patients had available data for $\geq 36$ months after vaccine initiation.

A limitation of using the CPRD is that the EHR data are recorded for clinical purposes rather than specifically for research purposes. Moreover, as the CPRD data comprise EHRs from general practices, only the vaccinations received at those practices would be reliably recorded, while vaccinations administered in other settings such as hospitals, pharmacies, travel clinics, or occupational health services may have been missed. As for all observational studies, there is the potential for selection bias and possibility of unmeasured confounders. Another limitation is related to the comparison of completion for the selected two-dose and three-dose vaccines. The hepatitis A series has a longer window for completion than the combined A/ $B$ series, which could lead to higher completion within the recommended window. Finally, we did not examine, hence do not report, characteristics of the study population beyond sex, age, and UK region.

These limitations raise questions that would benefit from further study. In particular, a more complete capture to include all vaccinees from settings other than general practices and the reasons for these individuals initiating hepatitis vaccination series would be of great interest. We were unable to locate published population-level data for the UK regarding other settings, such as addiction or homeless services, and the reasons for hepatitis vaccinations (eg, for high-risk individuals, health care workers, travelers, etc.). As a corollary, it would be of interest to understand geographical vaccination patterns (eg, urban vs countryside) to identify areas of need. Finally, as noted above, better understanding of factors affecting adherence and of effective initiatives to improve adherence are needed to counter the potential waste of health care resources that occurs with suboptimal protection from incomplete vaccination series.

\section{Conclusions}

Adherence and series completion rates are low for hepatitis $\mathrm{A}$, hepatitis $\mathrm{B}$, and hepatitis $\mathrm{A} / \mathrm{B}$ multi-dose vaccines for adults in the UK. Series completion rates, even with extended observation windows, ranged from only 23 to $35 \%$. The majority of adults initiating hepatitis vaccination series in the UK may not be receiving the full protective benefit of these multi-dose vaccines because of receipt outside the optimal time frame or failure to complete the series. Work is needed to identify, understand, and address barriers to series completion for adults receiving multi-dose vaccines in real-world settings.

\section{Additional file}

Additional file 1: Figure S1. Flow chart depicting identification of individuals eligible for the study in the Clinical Practice Research Datalink (CPRD). (PDF 148 kb)

\section{Abbreviations}

95\% Cl: 95\% confidence interval; CPRD: Clinical Practice Research Datalink; EHR: Electronic health record; HR: Hazard ratio; IQR: Interquartile range; KM: Kaplan-Meier; NR: Not reached; UK: United Kingdom; US: United States

\section{Acknowledgments}

Medical writing and editorial assistance was provided by Elizabeth V. Hillyer, DVM. This assistance was funded by Merck Sharp \& Dohme Corp., a subsidiary of Merck \& Co., Inc., Kenilworth, NJ, USA

\section{Funding}

This study was sponsored by Merck Sharp \& Dohme Corp., a subsidiary of Merck \& Co., Inc., Kenilworth, NJ, USA. The funder of the study participated in the study design, analysis, data interpretation, decision to publish, and preparation of the manuscript. In addition, the funder provided support in the form of salaries for all authors.

\section{Availability of data and materials}

The dataset supporting the conclusions of this article was derived from the Clinical Practice Research Datalink (CPRD; http://www.cprd.com). The study protocol was approved by the CPRD Independent Scientific Advisory Committee (ISAC approval number 17_226R). Restrictions apply to the availability of these data, which were used under license for the current study with ISAC approval, and so are not publicly available. We do not have permission to give public access to these datasets; however, researchers may request access for their own purposes. Access to CPRD requests can be made via the CPRD website https://www.cprd.com/research-applications or via the enquiries email enquiries@cprd.com.

\section{Authors' contributions}

Conception and design of the study: KDJ, XL, DZ. Data analysis: DZ. Interpretation of findings, critical review, and revision of the manuscript: all authors. All authors read and approved the final manuscript.

\section{Ethics approval and consent to participate}

The protocol for use of Clinical Practice Research Datalink (CPRD) anonymized data was approved by the CPRD Independent Scientific Advisory Committee (ISAC reference number 17_226R).

Consent for publication

Not applicable.

\section{Competing interests}

KDJ and XL are employees of Merck \& Co., Inc., Kenilworth, NJ, USA. DZ was an employee of Merck at the time of the study.

\section{Publisher's Note}

Springer Nature remains neutral with regard to jurisdictional claims in published maps and institutional affiliations.

\section{Author details}

${ }^{1}$ Center for Observational and Real World Evidence (CORE), Merck \& Co., Inc., Kenilworth, NJ, USA. ${ }^{2}$ Center for Observational and Real World Evidence (CORE), Merck \& Co., Inc., UG2AB-30, 351 N. Sumneytown Pike, North Wales, PA 19454, USA. ${ }^{3}$ MSD Vaccines, Center for Observational and Real World Evidence (CORE), Lyon, France.

Received: 30 July 2018 Accepted: 21 March 2019

Published online: 15 April 2019

\section{References}

1. Gallagher KE, Kadokura E, Eckert LO, Miyake S, Mounier-Jack S, Aldea M, et al. Factors influencing completion of multi-dose vaccine schedules in adolescents: a systematic review. BMC Public Health. 2016;16:172.

2. Hill HA, Elam-Evans LD, Yankey D, Singleton JA, Kang Y. Vaccination coverage among children aged 19-35 months - United States, 2016. MMWR Morb Mortal Wkly Rep. 2017;66(43):1171-7.

3. Tauil Mde C, Sato AP, Waldman EA. Factors associated with incomplete or delayed vaccination across countries: a systematic review. Vaccine. 2016;34(24):2635-43. 
4. Carrillo-Santisteve P, Tavoschi L, Severi E, Bonfigli S, Edelstein M, Bystrom E, et al. Seroprevalence and susceptibility to hepatitis A in the European Union and European Economic Area: a systematic review. Lancet Infect Dis. 2017;17(10):e306-e19.

5. Craig AS, Schaffner W. Prevention of hepatitis $A$ with the hepatitis $A$ vaccine. N Engl J Med. 2004;350(5):476-81.

6. Schweitzer A, Horn J, Mikolajczyk RT, Krause G, Ott JJ. Estimations of worldwide prevalence of chronic hepatitis B virus infection: a systematic review of data published between 1965 and 2013. Lancet. 2015;386(10003): 1546-55.

7. Public Health England. Immunisation against infectious disease: the green book. https://www.gov.uk/government/collections/immunisation-againstinfectious-disease-the-green-book. Accessed 8 Feb 2019.

8. Public Health England. Hepatitis A: the green book, chapter 17. https:// www.gov.uk/government/publications/hepatitis-a-the-green-book-chapter17. Accessed 8 Feb 2019

9. Public Health England. Hepatitis B: the green book, chapter 18. https:// www.gov.uk/government/publications/hepatitis-b-the-green-book-chapter18. Accessed 8 Feb 2019

10. UK National Health Service. Vaccinations. https://www.nhs.uk/conditions/ vaccinations/. Accessed 8 Feb 2019

11. Williams WW, Lu PJ, O'Halloran A, Kim DK, Grohskopf LA, Pilishvili T, et al. Surveillance of vaccination coverage among adult populations - United States, 2015. MMWR Surveill Summ. 2017;66(11):1-28.

12. Bridges CB, Hurley LP, Williams WW, Ramakrishnan A, Dean AK, Groom AV. Meeting the challenges of immunizing adults. Vaccine. 2015;33 Suppl 4:D114-20.

13. Trantham L, Kurosky SK, Zhang D, Johnson KD. Adherence with and completion of recommended hepatitis vaccination schedules among adults in the United States. Vaccine. 2018;36(35):5333-9.

14. Nyamathi AM, Marlow E, Branson C, Marfisee M, Nandy K. Hepatitis A/B vaccine completion among homeless adults with history of incarceration. J Forensic Nurs. 2012;8(1):13-22.

15. Heywood AE, Nothdurft H, Tessier D, Moodley M, Rombo L, Marano C, et al. Pre-travel advice, attitudes and hepatitis $A$ and $B$ vaccination rates among travellers from seven countries. J Travel Med. 2016;24(1).

16. Yue X, Black CL, O'Halloran A, Lu PJ, Williams WW, Nelson NP. Hepatitis A and hepatitis $B$ vaccination coverage among adults with chronic liver disease. Vaccine. 2018;36(9):1183-9.

17. Medicines \& Healthcare products Regulatory Agency. Clinical Practice Research Datalink http://www.cprd.com/home/. Accessed 8 Feb 2019

18. VAQTA ${ }^{\circledast}$ adult prescribing information. https://www.medicines.org.uk/emc/ product/1396/smpc. Accessed 8 Feb 2019.

19. UK National Health Service. Which vaccinations are free? https://www.nhs.uk/chq/ Pages/1040.aspx?CategoryID=67\&SubCategoryID=152. Accessed 8 Feb 2019.

20. Nelson JC, Bittner RC, Bounds L, Zhao S, Baggs J, Donahue JG, et al. Compliance with multiple-dose vaccine schedules among older children, adolescents, and adults: results from a vaccine safety datalink study. Am J Public Health. 2009;99(Suppl 2):S389-97.

21. Brim N, Zaller N, Taylor LE, Feller E. Twinrix vaccination schedules among injecting drug users. Expert Opin Biol Ther. 2007;7(3):379-89.

22. Poulos RG, Ferson MJ, Orr KJ, McCarthy MA, Botham SJ, Stern JM, et al. Vaccination against hepatitis $A$ and $B$ in persons subject to homelessness in inner Sydney: vaccine acceptance, completion rates and immunogenicity. Aust N Z J Public Health. 2010;34(2):130-5.

23. Wong J, Payne M, Hollenberg S. A double-dose hepatitis B vaccination schedule in travelers presenting for late consultation. J Travel Med. 2014:21(4):260-5.

24. Lu PJ, O'Halloran AC, Williams WW, Nelson NP. Hepatitis B vaccination coverage among adults aged $\geq 18$ years traveling to a country of high or intermediate endemicity, United States, 2015. Vaccine. 2018;36(18):2471-9.

25. Reynolds GL, Nguyen HH, Singh-Carlson S, Fisher DG, Odell A, Xandre P. Application of the extended health control belief model to predict hepatitis A and B vaccinations. Public Health Nurs. 2016;33(5):430-9.

26. Topp L, Day CA, Wand H, Deacon RM, van Beek I, Haber PS, et al. A randomised controlled trial of financial incentives to increase hepatitis $B$ vaccination completion among people who inject drugs in Australia. Prev Med. 2013;57(4):297-303

27. Day CA, Shanahan M, Wand H, Topp L, Haber PS, Rodgers C, et al Development of immunity following financial incentives for hepatitis $B$ vaccination among people who inject drugs: a randomized controlled trial. J Clin Virol. 2016;74:66-72.
28. Rock C, de Barra E, Sadlier C, Kelly S, Dowling C, McNally C, et al. Impact of a new vaccine clinic on hepatitis $B$ vaccine completion and immunological response rates in an HIV-positive cohort. J Infect Public Health. 2013;6(3):173-8.

29. Shim M, Khaykis I, Park J, Bini EJ. Susceptibility to hepatitis A in patients with chronic liver disease due to hepatitis C virus infection: missed opportunities for vaccination. Hepatology. 2005;42(3):688-95.

30. Thudi K, Yadav D, Sweeney K, Behari J. Physicians infrequently adhere to hepatitis vaccination guidelines for chronic liver disease. PLoS One. 2013;8(7):e71124

31. Leite A, Thomas SL, Andrews NJ. Implementing near real-time vaccine safety surveillance using the Clinical Practice Research Datalink (CPRD). Vaccine. 2017;35(49 Pt B):6885-92.

32. Herrett E, Gallagher AM, Bhaskaran K, Forbes H, Mathur R, van Staa T, et al Data resource profile: Clinical Practice Research Datalink (CPRD). Int J Epidemiol. 2015:44(3):827-36.

33. Dayan GH, Shaw KM, Baughman AL, Orellana LC, Forlenza R, Ellis A, et al. Assessment of delay in age-appropriate vaccination using survival analysis. Am J Epidemiol. 2006;163(6):561-70.

34. Lanes S, Quinlan SC, Mast TC, Greenland S, Holick CN. Assessing bias in administrative database studies of RotaTeq vaccine completion due to exclusion of subjects with incomplete follow-up. Emerg Themes Epidemiol. 2015:12:5

\section{Ready to submit your research? Choose BMC and benefit from:}

- fast, convenient online submission

- thorough peer review by experienced researchers in your field

- rapid publication on acceptance

- support for research data, including large and complex data types

- gold Open Access which fosters wider collaboration and increased citations

- maximum visibility for your research: over $100 \mathrm{M}$ website views per year

At BMC, research is always in progress.

Learn more biomedcentral.com/submissions 